\title{
Urinary 1-hydroxypyrene in coke oven workers relative to exposure, alcohol consumption, and metabolic enzymes
}

\begin{abstract}
J Zhang, M Ichiba, K Hara, S Zhang, T Hanaoka, G Pan, Y Yamano, K Takahashi, K Tomokuni
\end{abstract}

\section{Objectives} Objectives-To investigate the influence
of personal lifestyle-such as smoking
and alcohol consumption-on urinary and alcohol consumption-on urinary 1-hydroxypyrene (1-OHP) concentrations in coke oven workers exposed to polycyclic aromatic hydrocarbons (PAHs) and to evaluate the association of 1-OHP concentrations with the genetic polymorphism of several metabolic enzymes including cytochrome P-450 (CYP) $1 \mathrm{A1}$ and glutathione S-tranferases (GSTs).
Methods-The study population contained 162 coke oven workers and 58 controls employed at the largest iron and
steel factory in China. Personal data were at the interview. 1-OHP in urine was measured with high performance liquid chromatography with fluorescence detection. Genetic polymorphisms were identified by the polymerase chain reaction (PCR) method.

Results-A positive association between excretion of urinary 1-OHP and the levels of exposure to PAHs was confirmed. Those people who consumed $\geqslant 50$ g/day ethanol had significantly higher 1-OHP excretion than did other coke oven workers $(p<0.01)$. No significant difference in urinary 1-OHP was found between smokers and non-smokers, in both controls and exposed subjects. The variant homozygotes at exon 7 of the CYP1A1 gene had significantly higher urinary 1-OHP concentrations than other CYP1A1 genotypes among the exposed workers $(p=0.03)$. There was less association between the concentrations of 1-OHP and the GSTM1, GSTP1, or GSTT1 polymorphism.

Conclusions-The present study confirmed that urinary 1-OHP is a good biomarker for exposure to PAHs. Alcohol consumption affected urinary 1-OHP excretion. The variant genotypes of the CYP1A1 gene may result in the enhancement of PAH metabolites. It is helpful to understand the role of individual susceptibility on metabolism of carcinogens. These findings suggest that the modulating effect of individual lifestyle factors or genetic nature should be considered in future studies on occupational exposure to PAHs and in evaluating the health risk from harmful chemicals. (Occup Environ Med 2001;58:716-721)
Keywords: 1-hydroxypyrene; genetic polymorphism; alcohol drinking

Coke oven workers are regularly exposed to many types of coke oven emissions, which are comprised mainly of polycyclic aromatic hydrocarbons (PAHs). 1-Hydroxypyrene (1OHP), a metabolite of pyrene that reflects the total uptake of PAHs, can be used as a biomarker of internal dose to assess recent exposure to PAHs. ${ }^{12}$ Increased urinary concentrations of 1-OHP have been shown in several occupational populations exposed to PAHs, including coke oven workers. ${ }^{2}{ }^{3}$ However, a wide variation in 1-OHP excretion between people was also found. Van Rooij et $a l^{4}$ examined the relative contribution of different sources to daily pyrene intake in volunteers who were not occupationally exposed to PAHs. They found that cigarette smoke and foods containing PAHs only accounted for a small part of the variation in urinary $1-\mathrm{OHP}$, although most pyrene intake was related to smoking and diet. Therefore, it is interesting to investigate whether other lifestyle factors or individual genetic nature could explain some of the variation in excretion of 1-OHP.

Of many lifestyle factors contributing to the source of pyrene intake, cigarette smoke and dietary habit are thought to be relatively important, and have been most often studied. Also, many epidemiological studies reported that alcohol misuse may increase the risk of various cancers, particularly when heavy drinking is combined with other risk factors - such as smoking and exposure to $\mathrm{PAH}$ compounds. ${ }^{5-7}$ One of the prime mechanisms through which alcohol induces cancer is related to the stimulatory effect of ethanol on microsomal cytochrome $P$-450 (CYP) enzyme activity which may result in enhanced concentrations of metabolites of procarcinogens. ${ }^{8}$

The polymorphism of metabolising enzymes has been suggested to interpret individual differences in the rate of activation or inactivation of carcinogens related to PAHs. The phase 1 enzymes - such as CYP - are known to catalyse the formation of reactive intermediates of some carcinogens, while phase 2 enzymessuch as glutathione S-transferases (GSTs) briefly participate in the detoxification of these intermediates through conjugation and excretion. Previous studies have confirmed that the pyrene is mainly oxidised by CYP enzymesfor example, CYP1A1 and CYP1B to phenols, dihydrodiols, and diphenols-which can form 
such water soluble secondary metabolites as glucuronides, sulfates, or glutathione conjugates. $^{9-11}$ Although the GST enzymes do not directly participate in the metabolism of 1-OHP, they may alter the concentrations of other pyrene derivatives, and affect the conversion of pyrene to 1-OHP. The genetic polymorphisms of CYP1A1 and GSTs have been associated with increased risk of cancer and increased PAH-DNA adducts, an indicator reflecting the actual biologically effective dose. ${ }^{12-16}$ Also, there are a growing number of surveys that investigate the relation of $\mathrm{PAH}$ metabolites such as 1-OHP with the polymorphism of CYP1A1 and GSTs. ${ }^{17-19}$ However, it is still limited and results are inconsistent.

The objective of this study was to investigate the influence of smoking and alcohol consumption on the excretion of urinary 1-OHP in coke oven workers and in unexposed controls. We also evaluated the association of 1-OHP concentrations with genetic polymorphism of several metabolic enzymes including CYP1A1, GSTM1, GSTP1, and GSTT1.

\section{Subjects and methods}

STUDY POPULATION AND SAMPLE COLLECTION The study was carried out at the largest coke plant in China, which has 17 coke ovens and $>1300$ employees exposed to coke oven emissions. The coke plant was described in a recent paper. ${ }^{3}$ To select the subjects for study, a simple self administered questionnaire survey was performed among the coke oven workers and unexposed workers. For the exposed group, coke oven workers working at different areas (bottom, middle, and top) of the oven, which have been shown to be correlated with the concentrations of PAH exposure, ${ }^{3}$ were randomly selected. The subjects from bottom (56), middle (55), and top (51) work areas were defined as low, middle, and high exposures, respectively. The controls were recruited from workers who were employed in repair and maintainance of electronic devices in the same plant. They were known to have no work related exposure to PAHs. The final study population consisted of 162 coke oven workers and 58 controls, all men. All participants in this study were recruited on a voluntary basis. They gave their informed consent.

Coke production is continuous ( $24 \mathrm{~h} /$ day), and each work cycle consisted of 8 days and three different shifts: two consecutive morning shifts and two consecutive afternoon shifts in the first 4 days, 5th day off duty, two consecutive night shifts, and then rest on the 8th day. The workers served on one shift for 4-8 hours.

A detailed questionnaire was completed by participants. Interviews were conducted by two trained interviewers using a structured questionnaire. Each was asked to indicate age, smoking, alcohol consumption, indoor air pollution (from the use of coal for cooking or heating), and histories of occupations and diseases.

Blood sampling was performed from 162 coke oven workers and 58 controls. Venous blood samples were drawn into ethylene diamine tetraacetic acid (EDTA) tubes, and white blood cells were collected after centrifugation. The DNA of the white blood cells was extracted with a commercial kit (Wako, Osaka, Japan) for identifying the genotypes of CYP1A1 and GSTs (GSTM1, T1, and P1). Spot urine samples were collected from each subject at the end of a 4-8 hour working period to examine urinary excretion of $1-\mathrm{OHP}$ and cotinine. All samples obtained were frozen and stored at $-70{ }^{\circ} \mathrm{C}$ until analyzed.

\section{ANALYTICAL METHODS}

1-OHP in urine

Excretion of 1-OHP in urine was measured as described by Hara et al. ${ }^{20}$ Briefly, the conjugated metabolite in a urine sample was hydrolysed with $\beta$-glucuronidase, and then the sample was measured by high performance liquid chromatography (HPLC) with fluorescence detection. Concentrations of 1-OHP were adjusted for creatinine, and expressed as $\mu \mathrm{mol} /$ mol creatinine.

\section{Cotinine in urine}

The concentration of urinary cotinine was measured by HPLC. ${ }^{21}$ Cotinine values were normalised for creatinine concentration.

\section{Identification of genotypes}

The Ile-Val polymorphism in exon 7 of the CYP1A1 gene was analyzed according to the method of Oyama et al. ${ }^{22}$ Subjects were divided into three groups corresponding to homozygous wild (Ile/Ile), heterozygous (Ile/Val), and homozygous mutant (Val/Val) types. The GSTM1 and GSTT1 genotyping were carried out essentially as described by Groppi et $a l^{23}$ and Nelson et al, ${ }^{24}$ respectively. The presence or absence of an amplification product results in two subgroups corresponding to GSTM1 and GSTT1 present or GSTM1 and GSTT1 absent. The A-G genotype at exon 5 of the GSTP1 gene was identified with the method proposed by Harries et al..$^{25}$ Subjects were categorised into three subgroups: homozygous wild (AA), heterozygous (AG), and homozygous mutant (GG) types. Several samples could not be genotyped due to failure to isolate DNA.

\section{STATISTICAL ANALYSES}

The 1-OHP and cotinine data were log transformed before statistical analysis. The comparison of means was carried out with Student's $t$ test or analysis of variance (ANOVA). Group differences in frequency for nominal variables were tested with the $\chi^{2}$ test. Correlation between 1-OHP and other continuous variables was calculated by Pearson's test. Multiple regression analysis was performed to evaluate the relation of 1-OHP concentration with exposure concentrations and some possible modulating factors. In this analysis, all of the questionnaire and examined variables were first analyzed against the 1-OHP concentrations with stepwise up regression analysis. The variables with an $F$ value $>1.0$ were included in the final model as independent variables. Two sided $\mathrm{p}$ values are given. 
Table 1 Summary data of study population

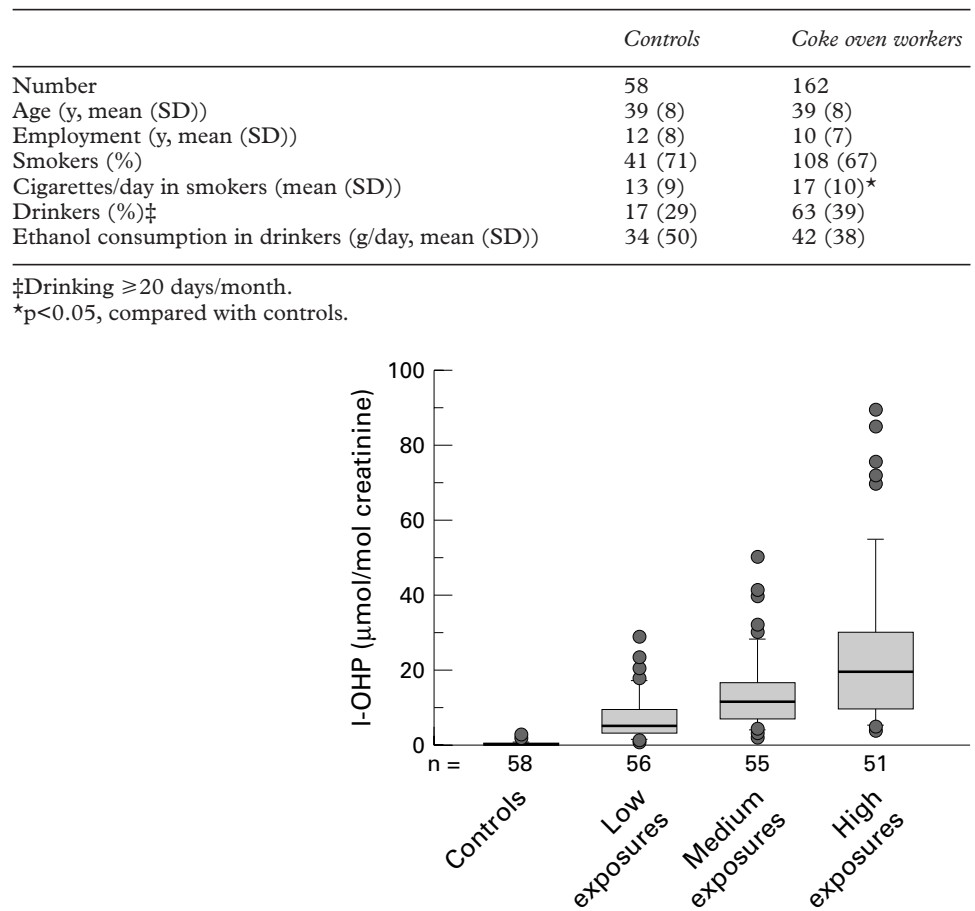

Figure 1 Urinary 1-OHP excretion in the controls and coke oven workers exposed to different PAH concentrations.

\section{Results}

The basic characteristics of exposed workers and controls are summarised in table 1. The distributions of age, years of employment, the prevalence of smoking, and alcohol consumption were similar between the two groups, except that number of cigarettes smoked/day was higher in coke oven workers.

The urinary concentrations of 1-OHP obtained from workers exposed to different $\mathrm{PAH}$ concentrations and controls are shown in figure 1. The geometric means of 1-OHP for all exposed workers and controls were 9.86 (range $0.8-89.8$ ) and 0.54 (range $0.1-2.8) \mu \mathrm{mol} / \mathrm{mol}$ creatinine, respectively. The highest concentration of urinary 1-OHP was detected in the group with high exposure. The median 1-OHP concentrations differed significantly between the four groups $(\mathrm{p}<0.0001)$.

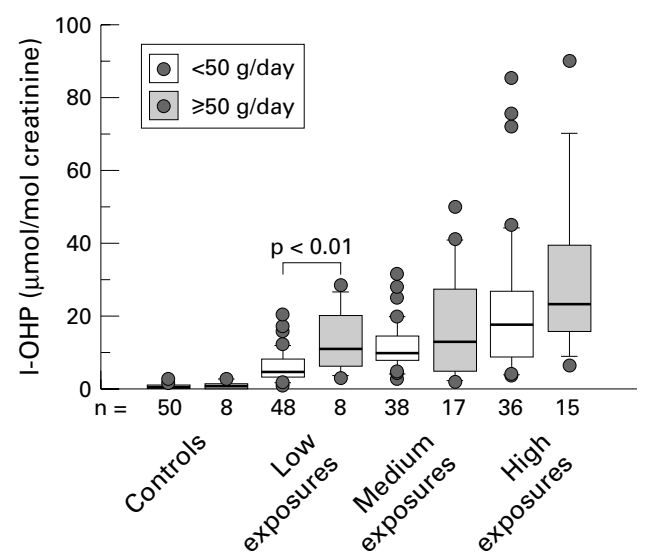

Figure 2 Comparison of urinary 1-OHP concentrations and the amount of ethanol consumed by different exposure groups.

Table 2 shows the results of urinary 1-OHP relative to cigarette smoke and alcohol consumption in exposed workers, after adjustment for exposure concentration, and controls. There were similar 1-OHP concentrations between smokers and non-smokers in both exposed subjects and controls. The subjects were then divided into three subgroups according to the concentrations of urinary cotinine: non-smokers, light smokers, and heavy smokers with <0.05, 0.05 0.9, and >0.9 nmol cotinine/mol creatinine, respectively. In the coke oven workers, 1-OHP concentrations tended to be highest among the heavysmokers, but this was not significant. Alcohol drinkers had slightly higher 1-OHP excretion than non-drinkers among the coke oven workers $(p=0.16)$. However, when the subjects were categorised with a cut off value of the daily average amount of ethanol ingested, people who consumed $\geqslant 50 \mathrm{~g} /$ day of ethanol had a significantly higher 1-OHP concentration than the people who consumed $<50 \mathrm{~g} /$ day ethanol $(p<0.01)$. This effect was significant in the group with low exposure after stratification by exposure concentrations $(\mathrm{p}<0.01)$, as shown in figure 2. The subjects consuming $\geqslant 50 \mathrm{~g} /$ day ethanol also had higher 1-OHP excretion than the subjects without such consumption in the high exposure group, although not significant

Table 2 1-OHP concentrations ( $\mu \mathrm{mol} / \mathrm{mol}$ creatinine) by smoking and alcohol consumption in controls and coke oven workers

\begin{tabular}{|c|c|c|c|c|c|c|}
\hline & \multicolumn{3}{|c|}{ Controls } & \multicolumn{3}{|c|}{ Coke oven workers * } \\
\hline & $n$ & $G M(25,75$ percentile $)$ & $p$ Value & $n$ & GM $(25,75$ percentile $)$ & $p$ Value \\
\hline All & 58 & $0.54(0.30,0.80)$ & & 162 & $9.86(5.00,18.40)$ & \\
\hline \multicolumn{7}{|l|}{ Smoking: } \\
\hline Never & 17 & $0.50(0.40,0.60)$ & \multirow[t]{2}{*}{0.58} & 53 & $10.74(5.28,20.43)$ & \multirow[t]{2}{*}{0.35} \\
\hline Ever & 41 & $0.56(0.30,1.00)$ & & 109 & $9.51(4.85,17.38)$ & \\
\hline \multicolumn{7}{|c|}{ Urinary cotinine ( $\mathrm{nmol} / \mathrm{mol}$ creatinine): } \\
\hline$<0.05$ & 21 & $0.60(0.40,0.85)$ & \multirow[t]{3}{*}{0.48} & 52 & $8.99(4.55,18.15)$ & \multirow[t]{3}{*}{0.32} \\
\hline $0.05-0.90$ & 19 & $0.58(0.40,0.95)$ & & 53 & $9.55(4.65,16.70)$ & \\
\hline$>0.90$ & 18 & $0.45(0.30,0.70)$ & & 57 & $11.17(7.33,21.48)$ & \\
\hline \multicolumn{7}{|c|}{ Alcohol consumption: } \\
\hline Non-drinkers & 41 & $0.51(0.30,0.73)$ & \multirow[t]{2}{*}{0.37} & 99 & $9.25(4.90,16.80)$ & \multirow[t]{2}{*}{0.16} \\
\hline Drinkers $\dagger$ & 17 & $0.63(0.40,1.02)$ & & 63 & $11.04(5.15,23.10)$ & \\
\hline \multicolumn{7}{|c|}{ Mean consumption of ethanol (g/day): } \\
\hline$<50$ & 50 & $0.52(0.30,0.80)$ & \multirow[t]{2}{*}{0.35} & 122 & $9.02(4.90,16.80)$ & \multirow[t]{2}{*}{$<0.01$} \\
\hline$\geqslant 50$ & 8 & $0.69(0.40,1.55)$ & & 40 & $13.12(8.70,27.80)$ & \\
\hline
\end{tabular}

GM=geometric mean.

${ }^{\star} \mathrm{GM}$ data were adjusted for levels of exposure.

†Drinking $\geqslant 20$ days/month. 
Table 3 Urinary 1-OHP concentrations ( $\mu$ mol/mol creatinine) by polymorphism of metabolic enzymes in the controls and exposed workers

\begin{tabular}{|c|c|c|c|c|c|c|}
\hline & \multicolumn{3}{|c|}{ Controls } & \multicolumn{3}{|c|}{ Coke oven workerst } \\
\hline & $n$ & GM $(25,75$ percentile $)$ & $p$ Value & $n$ & GM $(25,75$ percentile $)$ & $p$ Value \\
\hline \multicolumn{7}{|l|}{ CYP1A1: } \\
\hline Ile/Ile & 29 & $0.55(0.30,1.03)$ & \multirow[t]{3}{*}{$0.86 \ddagger$} & 76 & $9.91(5.83,20.23)$ & \multirow[t]{3}{*}{$0.03 \ddagger$} \\
\hline $\mathrm{Ile} / \mathrm{Val}$ & 14 & $0.63(0.50,0.80)$ & & 56 & $10.38(5.08,18.23)$ & \\
\hline $\mathrm{Val} / \mathrm{Val}$ & 4 & $0.63(0.35,1.45)$ & & 7 & $24.77(10.63,25.78)^{\star \star}$ & \\
\hline \multicolumn{7}{|l|}{ GSTM1: } \\
\hline Present & 18 & $0.71(0.50,1.20)$ & \multirow[t]{2}{*}{0.14} & 58 & $10.52(5.00,17.50)$ & \multirow[t]{2}{*}{0.91} \\
\hline Null & 30 & $0.52(0.30,0.80)$ & & 82 & $10.67(5.65,22.30)$ & \\
\hline \multicolumn{7}{|l|}{ GSTT1: } \\
\hline Present & 18 & $0.54(0.30,1.00)$ & \multirow[t]{2}{*}{0.54} & 61 & $10.07(5.53,20.35)$ & \multirow[t]{2}{*}{0.31} \\
\hline Null & 30 & $0.62(0.40,0.90)$ & & 78 & $11.46(6.45,19.60)$ & \\
\hline \multicolumn{7}{|l|}{ GSTP1: } \\
\hline AA & 31 & $0.54(0.30,0.95)$ & \multirow[t]{3}{*}{$0.57 \ddagger$} & 92 & $10.28(5.53,20.68)$ & \multirow[t]{3}{*}{$0.62 \ddagger$} \\
\hline AG & 15 & $0.69(0.50,0.98)$ & & 41 & $11.32(6.10,19.20)$ & \\
\hline GG & 2 & $0.58(0.50,0.70)$ & & 6 & $8.47(4.10,13.10)$ & \\
\hline
\end{tabular}

${ }^{\star \star} \mathrm{p}<0.01 v$ Ile/Ile type; $\mathrm{p}=0.01$ ille/Val type.

†Data were adjusted for levels of exposure.

$\ddagger$ ANOVA.

$\mathrm{GM}=$ geometric mean

$(p=0.11)$. Most drinkers were also tobacco smokers. The same analysis was also carried out with simultaneous adjustment for smoking habit or urinary cotinine concentrations, and the results were similar (data not shown). The influence of excess alcohol consumption on 1-OHP concentrations was not found in the controls. No significant relation between the urinary 1-OHP and indoor air pollution (coal use for cooking or heating) was found (data not shown).

The effect of genetic polymorphism on 1-OHP excretion is presented in table 3. For the CYP1A1 gene, there were significant differences in urinary 1-OHP concentrations among three genotypes in the exposed workers $(p=0.03)$. The workers carrying the $\mathrm{Val} / \mathrm{Val}$ genotype had significantly higher concentrations of $1-\mathrm{OHP}$ than did the Ile/Ile $(\mathrm{p}<0.01)$ and Ile/Val $(p=0.01)$ carriers. There were slightly higher 1-OHP concentrations in controls with GSTM1 present compared with those without GSTM1 $(p=0.14)$. By contrast, the other polymorphisms of metabolic enzymes examined were not found to be significantly associated with the urinary excretion of 1-OHP.

To investigate the simultaneous effects of exposure to PAHs and possible confounding factors, multiple regression analysis on the urinary 1-OHP was applied in the exposed workers (table 4). Based on the stepwise up regression analysis, six independent variables were entered into the final model. The results

Table 4 Multiple regression analysis for the effect of several selected variables on urinary $1-O H P$ excretion in coke oven workers $(n=127, R=0.66, p<0.0001)$

\begin{tabular}{lllll}
\hline & $\begin{array}{l}\text { Standard } \\
\text { regression } \\
\text { coefficient }\end{array}$ & SEM & t Value & $p$ Value \\
\hline Variables & 0.72 & 0.25 & 2.87 & $<0.01$ \\
Intercept & 0.61 & 0.03 & 8.54 & $<0.0001$ \\
EAH exposure concentration & 0.19 & $<0.01$ & 2.60 & 0.01 \\
Urinary cotinime & 0.07 & 0.03 & 0.96 & 0.34 \\
Alcohol consumption* & 0.16 & 0.06 & 2.24 & 0.03 \\
CYP1A1 polymorphism $\dagger$ & 0.17 & 0.12 & 2.34 & 0.02 \\
GSTT1 polymorphism $\ddagger$ & 0.13 & 0.06 & 1.85 & 0.07 \\
\hline
\end{tabular}

$\star$ Ethanol $\geqslant 50 \mathrm{~g} /$ day $v<50 \mathrm{~g} /$ day.

$+\mathrm{Val} / \mathrm{Val} v \mathrm{Ile} / \mathrm{Il}$ and Ile/Val.

$\ddagger$ GSTT1 present $v$ GSTT1 null. showed that exposure to PAHs was a good predictor for the concentrations of urinary 1-OHP. Diration of employment, excess alcohol intake, and CYP1A1 polymorphism also helped to explain the differences in urinary 1-OHP. There was a small effect of the GSTT1 genotype on the concentrations of 1-OHP. Urinary cotinine was not a significant predictor of 1-OHP.

\section{Discussion}

We found a significantly positive association between urinary excretion of 1-OHP and the concentrations of exposed PAHs, and confirmed additionally that the measurement of 1-OHP in urine is an available biomarker for evaluating the exposure to PAHs. To estimate individual risks from PAHs, we simultaneously examined whether personal lifestyle - such as smoking and alcohol consumption - and metabolic susceptibility genes including CYP1A1 and GSTs may affect the urinary concentrations of 1-OHP. Although pyrene itself does not show carcinogenic or mutagenic potencies, it is presumed that the conclusions obtained from the present study can be extended to other related carcinogenic $\mathrm{PAH}$ compounds such as benzo(a)pyrene (BaP).

The stimulatory effect of ethanol on microsomal mono-oxygenases through induction of the CYP2E1 form has been confirmed by animal experiments. ${ }^{8}{ }^{26}$ This effect is usually used to explain why ethanol can mediate the conversion of procarcinogens into their reactive species. A study described by Lieber et $a l^{27}$ showed that treatment of rodents with ethanol produced an enhancement of the ability to metabolise the components contained in cigarette smoke-such as PAHs. Although the role of CYP2E1 enzymes in metabolism of pyrene still remains unclear, they seem to be associated with the secondary oxidation of pyrene to cause indirectly the increase of 1-OHP concentrations. $^{9}$ The present study showed that alcohol drinking was a significant predictor of urinary 1-OHP in exposed workers, especially in heavy drinkers who consumed $\geqslant 50 \mathrm{~g} /$ day ethanol. In the present population, habitual 
alcohol consumption mainly comprised drinking beer and spirits, and ingestion of ethanol from spirits accounted for a larger proportion of the total ethanol consumed by heavy drinkers. We considered that there may be no significant differences in fluid intake by drinking beer between heavy drinkers and the others, and thus the influence of urinary volume on urinary 1-OHP excretion can be excluded. Similarly, we recently reported an influence of ethanol ingestion on urinary $1-\mathrm{OHP}$ in this plant but in different subjects. ${ }^{28}$ Moreover, it is of interest that in the same plant we also found that increased concentrations of DNA adducts in white blood cells was related to drinking alcohol. ${ }^{12}$ Jongeneelen et $a l^{29}$ did not find an effect of alcohol consumption on the toxicokinetics of pyrene in coke workers. Two other studies also did not show any relation between alcohol intake and urinary $1-\mathrm{OHP} .^{18} 30$ However, it is important to note the differences in analyses of drinking among these studies. Previous studies did not consider consumed dose of alcohol, or used lower amounts of ethanol consumed as the cut off value. In the present population studied, the prevalence of heavy drinkers ( $\geqslant 50 \mathrm{~g}$ ethanol/day) was relatively higher (about 22\%). This may have allowed the influence of alcohol consumption on 1-OHP excretion to be readily seen. In a cohort study of a middle aged Japanese population, Tsugane et $a l^{\beta 1}$ indicated that moderate alcohol consumption was associated with the lowest risk of mortality from all cancers, whereas the highest risk was found among heavy drinkers. These findings suggested that dose of alcohol is more important and should be taken into consideration when examining the effect of alcohol consumption on metabolism of carcinogens.

The association between cigarette smoke and 1-OHP concentrations is controversial. Zhao et $a l^{32}$ reported a greater smoking related increase in urinary 1-OHP among coke workers. Also, the dose-response relation between the number of cigarettes smoked and urinary 1-OHP concentrations has been shown. ${ }^{4}$ However, smoking was not found to be an important source of exposure to pyrene in several studies. ${ }^{33} 34$ From our results, smoking is not an important factor to explain the differences between 1-OHP excretion among the coke oven workers and unexposed controls. This finding may be partially due to the relatively higher exposure to PAHs, which may hide the effect of smoking on 1-OHP concentrations, because the mean concentrations of urinary 1-OHP measured from the present coke oven workers and controls were about fivefold higher than those previously reported. $^{29}$

It is well known that the CYP1A1 gene codes for the aryl hydrocarbon hydroxylase, which catalyses the oxygenation of PAH components. Jacob et al have examined the role of the CYP system in oxidation of pyrene using corresponding agents inducing different types of CYP enzymes in rat liver microsomes, and showed that $1-\mathrm{OHP}$ was the predominating metabolite as treated with CYP1A family inducers-for example, benzo-a-pyrene or 5, 6-benzoflavone. On the other hand, Crofts et $a l^{35}$ recently showed that the variant genotypes at exon 7 of the CYP1A1 gene showed a threefold increase in CYP1A1 enzymatic activity. This functional significance is thus supposed to cause an increase in concentrations of pyrene metabolites such as 1-OHP in the variant genotypes of CYP1A1. In the present study, a modulating effect of the CYP1A1 polymorphism on the concentrations of urinary 1-OHP was found in coke oven workers, as expected. The mean urinary 1-OHP concentration in the homozygous mutant type of CYP1A1 (Val/Val type) was twofold higher than in the other types (Ile/Ile and Ile/Val). In the other instances, a study of coke oven workers from Taiwan reported that the subjects with the homozygous variant genotype for CYP1A1 Msp I had a twofold increase in 1-OHP concentrations after the shift than the combined wild and heterozygous types. ${ }^{18}$ Similarly, the results found in aluminum smelter workers showed a slight rise in concentrations of 1-OHP in people with the CYP1A1 Val allele. ${ }^{19}$ The role of GST enzymes in biotransformation of $1-\mathrm{OHP}$ is incompletely understood. GSTM1 and GSTP1 (the most abundant GST in human lung) are active towards many epoxides through glutathione conjugation, whereas GSTT1 briefly conjugates smaller compounds. ${ }^{36}$ Epidemiological surveys showed that the effect of GST genetic polymorphism on 1-OHP excretion was uncertain. ${ }^{170} 37$ The present study indicated a slight increase in urinary 1-OHP in unexposed controls with the GSTM1 gene (table 3) and in exposed subjects with the GSTT1 gene (table 4). No systematic influence of the GSTP1 genotypes was found. Hong et $a l^{\beta 0}$ recently indicated that GSTM1 deficiency was associated with relatively higher urinary 1-OHP concentrations, but conflicting reports were also published. ${ }^{17}{ }^{37}$ However, a usual comment in these studies is that the GST polymorphism may not or only marginally influence 1-OHP excretion. This is compatible with our results.

In summary, the present study confirmed that urinary 1-OHP is a good biomarker for exposure to PAHs. We also found an effect of CYP1A1 polymorphism on urinary 1-OHP. It is helpful to understand the role of individual susceptibility on metabolism of carcinogens. Excess alcohol consumption may result in the enhancement of PAH metabolites, but further study on the mechanism is needed. Our findings suggest that these modulating factors should be taken into consideration in future studies on occupational exposure to PAHs and in evaluating the health risk from harmful chemicals.

We are grateful to D Guan (Angang Public Health and Anti-epidemic Station, China) and G Gao (Angang Occupational Hygiene Institute, China) for their help in epidemiological survey and sampling. We also thank $\mathrm{K}$ Takahashi (Saga cal survey and sampling. We also thank $\mathrm{K}$ Takahashi (Saga Medical School, Japan) for her technical assistance. This work was supported in part by a Grant in Aid for Scientific Research from the Ministry of Education, Science, Sports and Culture,
Japan. 
1 Jongeneelen FJ, Anzion RBM, Henderson PT. Determination of hydroxylated metabolites of polycyclic aromatic hydrocarbons in urine. F Chromatogr 1987;413:227-32.

2 Jongeneelen FJ, Anzion RBM, Scheepers PTJ, et al. 1-Hydroxypyrene in urine as a biological indicator of exposure to polycyclic aromatic hydrocarbons in several work environments. Ann Occup Hyg 1988;3:35-43.

3 Pan G, Hanaoka T, Yamano Y, et al. A study of multiple biomarkers in coke oven workers-a cross-sectional study in China. Carcinogenesis 1998;19:1963-68.

4 Van Rooij JGM, Veeger MMS, Bodelier-Bade MM, et al. Smoking and dietary intake of polycyclic aromatic hydrocarbons as sources of interindividual variability in the baseline excretion of 1-hydroxypyrene in urine. Int Arch Occup Environ Health 1994;66:55-65.

5 International Agency for Research on Cancer. IARC Monographs on the Evaluation of Carcinogenic Risk of Chemicals to humans. Alcohol Drinking 1986;Vol.44, IARC. Lyon, France.

6 Blot WJ. Alcohol and cancer. Cancer Res 1992;52 (Suppl.): 2119s-23s.

7 Lieber EL, Seitz HK, Garro AJ, et al. Alcohol related diseases and carcinogenesis. Cancer Res 1979;39:2836-86.

8 Gonzalaz FJ, Gelboin HV. Role of human cytochromes P-450 in the metabolic activation of chemical carcinogens and toxins. Drug Metab Rev 1994;26:165-83.

9 Jacob J, Grimmer G, Raab G, et al. The metabolic of pyrene by rat liver microsomes and the influence of various monooxygenase inducers. Xenobiotica 1982;12:45-53.

10 Boyland E, Sims P. Metabolism of polycyclic compounds: the metabolism of pyrene in rats and rabbits. Biochem $f$ 1964;90:391-98.

11 Strickland PT, Kang D, Bowman ED, et al. Identification of 1-hydroxypyrene glucuronide as a major pyrene metabolite in human urine by synchronous fluorescence spectroscopy and gas chromatography-mass spectrometry. Carcinogenesis 1994;15:483-87.

12 Kawajiri K, Nakachi K, Imai K, et al. Identification of genetically high risk individuals to lung cancer by DNA genetically high risk individuals to lung cancer by DNA
polymorphisms of the cytochrome P4501A1 gene. FEBS 1990;263:131-33.

13 Nakachi K, Imai K, Hayashi S, et al. Polymorphisms of the CYP1A1 and glutathione S-transferase genes associated with susceptibility to lung cancer in relation to cigarette dose in a Japanese population. Cancer Res 1993;53:2994-99.

14 Mooney LVA, Bell DA, Santella RM, et al. Contribution of genetic and nutritional factors to DNA damage in heavy smokers. Carcinogenesis 1997;18:503-9.

15 Wang Y, Ichiba M, Iyadomi M, et al. Effects of genetic polymorphism of metabolic enzymes, nutrition, and lifestyle
factors on DNA adduct formation in lymphocytes. Ind Health 1998;36:337-46.

16 Zhang J, Ichiba M, Feng Y, et al. Aromatic DNA adducts in coke-oven workers, in relation to exposure, lifestyle and genetic polymorphism of metabolic enzymes. Int Arch Occup Environ Health 2000; 73:127-35.

17 Ovrebo S, Ryberg D, Haugen A, et al. Glutathione S-transferase M1 and P1 genotypes and urinary excretion of 1-hydroxypyrene in coke oven workers. Sci Total Environ of 1-hydroxypyrente

18 Wu MT, Huang SL, Ho CK, et al. Cytochrome P4501A1 Msp I polymorphism and urinary 1-hydroxypyrene concentrations in coke-oven workers. Cancer Epidemiol Biomark Prev 1998;7:823-29.

19 Alexandrie AK, Warholm M, Carstensen U, et al. CYP1A1 and GSTM1 polymorphisms affect urinary 1-hydroxypyrene levels after PAH exposure. Carcinogenesis 2000;21:669-76.

20 Hara K, Hanaoka T, Yamano Y, et al. Urinary 1-hydroxypyrene levels of garbage collectors with low-level exposure to polycyclic aromatic hydrocarbons. Sci Total Environ 1997;199:159-64.

21 Yamano Y, Tokutake T, Haga M, et al. Determination of cotinine by high performance liquid chromatography and evaluation of exposure to tobacco smoke. Proceedings of 63rd Annual Meeting of Japan Association of Industrial Health 1990;pp126 (in Japanese)

22 Oyama T, Mitsudomi T, Kawarmoto T, et al. Detection of CYP1A1 gene polymorphism using designed RFLP and distributions of CYP1A1 genotypes in Japanese. Int Arch Occup Environ Health 1995;67:253-56.

23 Groppi A, Coutelle C, Fleury B, et al. Glutathione $\mathrm{S}$-transferase class mu in French alcoholic cirrhotic patients. Hum Genet 1991;87:628-30.

24 Nelson HH, Wiencke JK, Christiani DC, et al. Ethnic differences in the prevalence of the homozygous deleted genotype of glutathione S-transferase theta. Carcinogenesis 1995;16:1243-45.

25 Harries LW, Stubbins MJ, Forman D, et al. Identification of genetic polymorphisms at the glutathione $\mathrm{S}$-transferase $\mathrm{Pi}$ locus and association with susceptibility to bladder, testicular and prostate cancer. Carcinogenesis 1997;18:641-44.

26 Wronska-Nofer T, Wisniewska-Knypl J, Wyszynska K, et al. Genotoxicity of industrial dyes under the inductive effect of ethanol on monooxygenase system in mice. Mutat Res 1997;392:229-35.

27 Lieber CS, Baraona E, Leo MA, et al. Metabolism and metabolic effects of ethanol, including interaction with drugs, carcinogens and nutrition. Mutat Res 1987;186:20133 .

28 Hara K, Hanaoka $\mathrm{T}$, Yamano $\mathrm{Y}$, et al. Urinary 1-hydroxypyrene as a biomarker for exposure to polycyclic aromatic hydrocarbons in Chinese coke oven workers. Nagoya Med f 1998;42:157-69.

29 Jongeneelen FJ, van Leeuwen FE, Oosterink S, et al. Ambient and biological monitoring of coke oven workers: determinants of the internal dose of polycyclic aromatic hydrocarbons. B F Ind Med 1990;47:454-61.

30 Hong YC, Leem JH, Park HS, et al. Variations in urinary 1-hydroxypyrene glucuronide in relation to smoking and the modification effects of GSTM1 and GSTT1. Toxicology Letters 1999;108:217-23.

31 Tsugane S, Fahey MT, Sasaki S, et al. Alcohol consumption and all-cause and cancer-mortality among middle-aged Japanese men: seven-year follow-up of the JPHC study Cohort I. Japan Public Health Center. Am f Epidemiology 1999;150:1201-07.

32 Zhao ZH, Quan WY, Tian DH. Urinary 1-hydroxypyrene as an indicator of human exposure to ambient polycyclic aromatic hydrocarbons in a coal-burning environment. Sci Total Environ 1990;92:145-54.

33 Elovaara E, Heikkila P, Pyy L, et al. Significance of dermal and respiratory uptake in creosote workers: exposure to polycyclic aromatic hydrocarbons and urinary excretion of 1-hydroxypyrene. Occup Environ Med 1995;52:196-203.

34 Malkin R, Kiefer M, Tolos W. 1-Hydroxypyrene levels in coal-handling workers at a coke oven. F Occup Environ Med 1996;38:1141-44.

35 Crofts F, Taioli E, Trachman J, et al. Functional significance of different human CYP1A1 genotypes. Carcinogenesis 1994:15:2961-63.

36 Ketterer B, Harris JM, Talaska G, et al. The human glutathione S-transferase supergene family, its polymorphism, and its effects on susceptibility to lung cancer. Environ Health Perspect 1992;98:87-94.

37 Merlo F, Andreassen A, Weston A, et al. Urinary excretion of 1-hydroxypyrene as a marker for exposure to urban air levels of polycyclic aromatic hydrocarbons. Cancer Epidemiol Biomark Prev 1998;7:147-56.

\section{Correspondence and editorials}

Occupational and Environmental Medicine welcomes correspondence relating to any of the material appearing in the journal. Results from preliminary or small scale studies may also be published in the correspondence column if this seems appropriate. Letters should be not more than 500 words in length and contain a minimum of references. Tables and figures should be kept to an absolute minimum. Letters are accepted on the understanding that they be subject to editorial revision and shortening.

The journal also publishes editorials which are normally specially commissioned. The Editor welcomes suggestions regarding suitable topics; those wishing to submit an editorial, however, should do so only after discussion with the Editor. 